\title{
S. F. Light
}

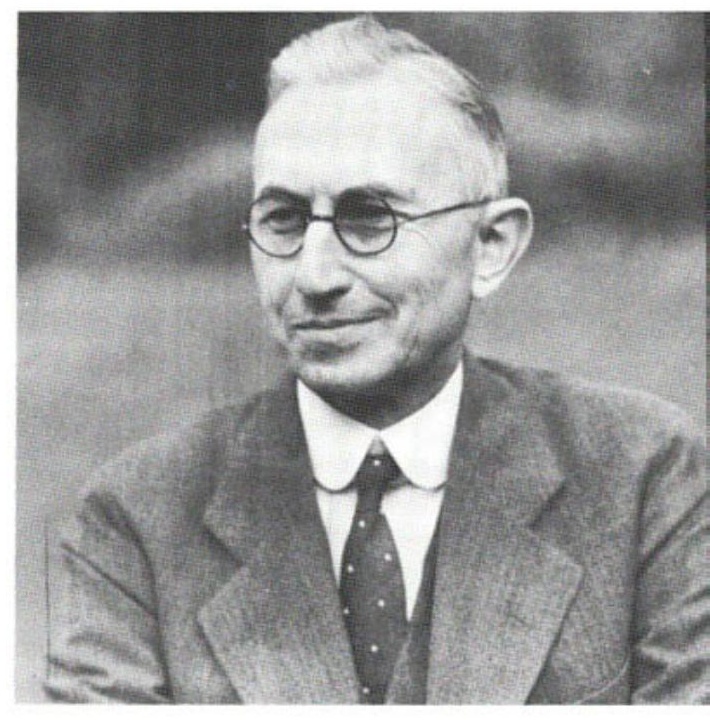

The late Professor S. F. Light (1886-1947) was for twenty-two years a member of the Department of Zoölogy at the University of California, Berkeley. His active interests ranged widely over the field of the invertebrates, and ran the gamut from taxonomy (alcyonarians, scyphozoans, termites, copepods) to the social physiology of termites, their protozoans, symbionts, and caste determination.

Dr. Light gave an extraordinary amount of time and careful thought to his teaching at all levels and exercised a peculiarly pervasive and long-lasting influence on his students' points of view, interests, and habits of thought. His advanced courses were marked by a critical, appreciative, phylogenetic morphology and a critical natural history which insisted on a full realization of the values of sound systematics, keen field observation, and concrete, testable interpretations. The essence of his natural history course was to be found between the lines of its syllabus, which combined a dynamic approach to basic principles (not only of invertebrate zoölogy but of field biology and scientific methodology) with practical aids to the mastery of a specific fauna. It was the result of more than ten years of active contact, virtually the year around, with that fauna and of continual efforts to perfect a teaching approach which aimed at very high and exacting goals. In the present manual, a conscientious updating of the original published syllabus, the revisers have, I believe, been successful in their aim of retaining the values of Light's approach.

Professor Light played his role in biology and academic life in personal contacts rather than in national or university affairs, and profoundly affected the attitudes of many graduate students and associates. Those who knew him will remember the personal characteristics of modesty-extending to a real underestimation of self-, of appreciation of disciplines which lay beyond his own field of study, of exacting criticism in the use of words and ideas - driving him now to caution, now to very forward positions-, of sincere interest in the human relations of his students and assistants, and of a highly developed aesthetic 
vi S. F. Light

enjoyment of outdoor beauty. Many have felt that although they never really knew the inner man, they sensed vividly the goals and standards for which he lived.

Theodore H. Bullock 